\title{
Nanoemulsion of orange oil with non ionic surfactant produced emulsion using ultrasonication technique: evaluating against food spoilage yeast
}

\author{
Saranya Sugumar $\cdot$ Sanjay Singh . \\ Amitava Mukherjee • N. Chandrasekaran
}

Received: 23 January 2015 / Accepted: 1 February 2015/Published online: 15 February 2015

(C) The Author(s) 2015. This article is published with open access at Springerlink.com

\begin{abstract}
In recent years, food industries have shown great interest in developing nanoemulsion (NE) using essential oils (EOs) to prevent food spoilage caused by microorganisms. The hydrophobic properties of EOs have lead to reduced solubilization effect of food, which in turn, created a negative impact on the quality of food and its antimicrobial efficacy. Focusing this issue, we attempted a unique NE preparation using orange oil, Tween 80 (organic phase) and water (aqueous phase) by sonication technique. Based on thermodynamic stability studies, the effective diameter was reported to be in the size range from 20 to $30 \mathrm{~nm}$. Saccharomyces cerevisiae was used in testing the anti-yeast effect. Their activity was studied in both growth medium and apple juice. The minimum inhibitory concentration of this NE was determined using broth dilution method. At $2 \mu \mathrm{l} / \mathrm{ml}$, orange oil NE demonstrated inhibition of tested microorganisms. The kinetics of killing curve, have shown that the NE treated cells had lost its viability within $30 \mathrm{~min}$ of interaction. Also, SEM image revealed that the treated cells became distorted in comparison to their control cells. NE treated apple juice showed complete loss of viability even on dilution as compared to their controls.
\end{abstract}

Keywords Orange oil - Ultrasonication · Nanoemulsion · Saccharomyces cerevisiae - Apple juice

S. Sugumar · S. Singh · A. Mukherjee · N. Chandrasekaran $(\bowtie)$ Centre for Nanobiotechnology, VIT University,

Vellore 632014, India

e-mail: nchandrasekaran@vit.ac.in

\section{Introduction}

Preservation of food quality and assuring consumer safety is the most significant concern in the food industry. Food products, especially those that are perishable, are easily contaminated by spoilage-causing microorganisms during preparation, storage and distribution. Thus, it must be protected to avoid sensory deterioration and to extend their shelf life (Rasooli 2007). However, the most serious concern is focused on the illness-causing foodborne pathogens. In some food preservation, the pathogen control strategies, including heating, refrigeration and addition of chemical antimicrobial compounds are being employed to make food safe for consumption (Davidson and Harrison 2002). One such approach involves the use of natural food grade antimicrobial compounds such as EOs (Naidu 2000). The essential oils (EOs) are highly aromatic and volatile liquids, usually extracted from the bark, leaves, stem or leaves of herbs and spices, with excellent antioxidant and antimicrobial properties. Also, they have reported against a broad spectrum of bacteria and fungi (Weiss et al. 2009; Burt 2004).

Food antimicrobials could be synthetically derived or from natural sources such as plants and microbes. These include phenolic compounds, terpenes, flavonoids, etc., which occurs in spices, and herbs. They can be sourced from over 1,300 plants such as thyme (thymol), oregano (carvacrol), clove (eugenol), orange (limonene), and cinnamon (cinnamaldehyde) (Chao et al. 2000; Velluti et al. 2003; Holley and Patel 2005). Phenolic compounds such as thymol, carvacrol and eugenol are known as EOs possessing the most potent antibacterial properties (GarcíaGarcía et al. 2011). Recent demonstration states that, the inhibition of a wide range of bacterial species, including, E. coli O157:H7, Listeria monocytogenes, Staphylococcus 
aureus, Salmonella typhymurium (Oussalah et al. 2007) and several other fungi by essential oil treatment (De Martino et al. 2009).

In food industries, EOs are used as natural antimicrobial compounds, and it serves the best substitution of synthetic chemical preservatives. The presence of bioactive compounds makes them biodegradable and biocompatible in nature. The antimicrobial activities of different EOs and their components have already been reported against various food pathogenic microorganisms (Sikkema et al. 1995; Helander et al. 1998; Di Pasqua et al. 2006; Gill and Holley 2006). However, direct incorporation of EOs in food produces organoleptic properties. It also has technological limitations such as hydrophobicity, reactivity and volatility of bioactive molecules constituting EOs (Huang et al. 2010). This problem might be overcome by formulating EOs into nanoemulsion that is transparent, and thus, could be applied to food and beverage products, thereby, decreasing the amount of the EOs required (Qian et al. 2012). Emulsions that have droplets in the size range of 20-200 nm are called nanoemulsions (Solans et al. 2005). The method of preparation determines the stability of the formulated nanoemulsion. Formulation of nanoemulsion can be done by two methods-low energy and high energy emulsification. In low energy emulsification process, the chemical properties of the emulsion system are exploited, thereby, converting a microemulsion into a nanoemulsion. High-pressure homogenization, microfluidization, and ultrasonication are the techniques that employ high energy emulsification. The method that is most widely used is ultrasonication because it is economical and easy to use (Tang et al. 2013).

Encapsulation of EOs with the help of a food grade emulsifier at the nanoscale represents a feasible technology to increase the physical and chemical stability of the bioactive compounds. Also, this process protects from interactions with the food components. Due to nano-sized droplets present in encapsulation, increasing their bioactivity through the activation of passive mechanisms of cell absorption (Weiss et al. 2009). Recently, there has been growing interest in utilizing nanoemulsions to encapsulate bioactive components for applications in food and beverage products (McClements 2011). Saccharomyces cerevisiae and Schizosaccharomyces pombe are listed among the most significant spoilage yeasts for fruit juices and soft drinks (Stratford 2006). The present study demonstrates a commercially feasible nanoemulsion technology to produce nanoscale system to deliver the antimicrobial components in food. The orange oil nanoemulsion was formulated and tested against the food spoilage yeast, $S$. cerevisiae. Further, the anti-yeast activities of the orange oil nanoemulsion in growth medium and apple juice were investigated.

\section{Materials and methods}

Materials

\section{Chemicals}

Orange oil (Citrus sinensis), potato dextrose broth and potato dextrose agar were purchased from Himedia, India. Tween 80, Bioxtra (Polyoxyethylene (20) sorbitan monolaurate) were purchased from Sigma-Aldrich, India. Ultrapure water was obtained from CascadaTM Biowater System, Pall Corporation, USA, with a resistivity of not less than $18.2 \mathrm{M} \Omega \mathrm{cm}$ was used in the preparation of all solutions. All other chemicals used were of analytical reagent grade.

\section{Microorganism}

The yeast strain, S. cerevisiae (MTCC 171), was purchased from National Chemical Laboratory (Pune, India). The strain was cultured in a $50 \mathrm{ml}$ potato dextrose agar at $37{ }^{\circ} \mathrm{C}$ for 2 days. $1 \mathrm{ml}$ of this grown culture was reinoculated again into a $50 \mathrm{ml}$ potato dextrose broth, and the growth was adjusted to $1 \times 10^{8}$ colony-forming units $(\mathrm{CFU}) / \mathrm{ml}$ at $600 \mathrm{~nm}$ using phosphate buffered saline (PBS).

\section{Method}

\section{Preparation of nanoemulsion}

Nanoemulsion was prepared to use orange oil, non ionic surfactant, and water. It was mixed at ratios of 1:4, 1:3, 1:2 and 1:1. The coarse emulsion was initially mixed with a magnetic stirrer at $140 \mathrm{rpm}$ under room temperature. This solution was further mixed using high energy method, ultrasonic horn processor. The system maintains a frequency of $20 \mathrm{kHz}$ with maximum output of $750 \mathrm{~W}$ that could be delivered with the flexible control of amplitude $40 \%$ (Sonics \& Materials, Inc., Newtown, USA). The tip was primarily made up of titanium alloy Ti-6Al-4 $\mathrm{V}$ and diameter of $13 \mathrm{~mm}$. It is used to amplify and radiate the ultrasonic energy into the sample. Emulsions were sonicated at ambient temperature for $10 \mathrm{~min}$, where, each cycle consisted of $30 \mathrm{~s}$ pulses on and $1 \mathrm{~s}$ pulses off.

\section{Particle size distribution and its polydispersity index}

The droplet size and size distribution of the selected orange oil nanoemulsion was determined using dynamic light scattering. The hydrodynamic size was measured using a particle size analyzer (90 plus Particle Size Analyzer, Brookhaven Instruments Corporations, USA). The nanoemulsion formed was diluted with double distilled water 
to avoid multiple scattering effects. The droplet size was described in terms of $\mathrm{nm}$ and the polydispersity index (PDI) was measured.

\section{Anti yeast activity}

\section{Well diffusion method}

A single isolated yeast colony was streaked onto the potato dextrose agar medium for $48 \mathrm{~h}$ prior to testing. A few colonies were inoculated into potato dextrose broth and it was adjusted to $10^{8} \mathrm{CFU} / \mathrm{ml}$ using PBS. Wells were made using sterile cork borer on the surface of agar plates of potato dextrose agar (Himedia) that was previously seeded by spreading $100 \mu \mathrm{l}$ of 0.1 OD adjusted culture. Orange oil nanoemulsion was stored at different temperatures such as $25,37,4$ and $-20{ }^{\circ} \mathrm{C}$; and was studied for different time interval of $0,24 \mathrm{~h}, 7,14,21$ and 28 days, respectively. A $100 \mu \mathrm{l}$ of sample was added to wells and the plates were incubated for $48 \mathrm{~h}$ at $28{ }^{\circ} \mathrm{C}$; and the diameter of the resulting zone of inhibition was measured in millimetres.

\section{Time kill analysis curve}

To study the anti-yeast activity of orange oil nanoemulsion on different time interval, standard plate count method was employed. Different concentrations of nanoemulsion ranging from 10-, 100- to 1,000-fold dilutions were made with 0.1 OD cells $\left(10^{8} \mathrm{CFU} / \mathrm{ml}\right)$. The interacted samples were taken after $30 \mathrm{~min}, 4$ and $24 \mathrm{~h}$ of incubation at room temperature. In brief, $0.1 \mathrm{ml}$ of each sample was used to prepare serial dilutions that were spread in duplicates on potato dextrose agar plates. The plates were incubated at room temperature for $48 \mathrm{~h}$. The colonies were counted and calculated by dilution times. Time-kill curves were plotted by monitoring the viability of cells in samples after 30 min, 4 and $24 \mathrm{~h}$ of incubation at room temperature.

\section{Effects of orange oil nanoemulsion on growth of yeast in $P D B$}

The MICs and MFCs of the orange oil nanoemulsion were determined by macro dilution assay. Orange oil nanoemulsion were added directly to Erlenmeyer flasks containing PDB medium $(40 \mathrm{ml})$ resulting in final concentrations of $0.0625-2 \mu \mathrm{l} / \mathrm{ml}$ in twofold increments $(2.5-80 \mu \mathrm{l})$. The flasks were inoculated with approximately $10^{7} \mathrm{CFU} / \mathrm{ml}$ yeast and $1 \mathrm{ml}$ of that was added to each flask, and then incubated at $30{ }^{\circ} \mathrm{C}$ for 24 or $48 \mathrm{~h}$. The MICs were taken as the lowest concentration at which no visible growth occurred in plate count assay.

\section{Microbial adhesion to hydrocarbon (MATH) assay}

The surface hydrophobicity of yeast cells with or without treatment of nanoemulsion was evaluated by MATH assay (Ly et al. 2008). In this experiment, $1.5 \mathrm{ml}$ of freshly grown $S$. cerevisiae cells that contain approximately $1 \times 10^{7} \mathrm{CFU} / \mathrm{ml}$ cells in PDB medium was collected by centrifugation and then resuspended in $1 \mathrm{ml}$ of orange oil nanoemulsion or PBS ( $\mathrm{pH}$ 7.4). After $2 \mathrm{~h}$ of treatment at room temperature, the yeast cells were centrifuged and then washed twice with PBS to remove the remaining treatment solutions. The yeast cells were then resuspended in PBS to achieve an initial absorbance $\left(A_{1}\right)$ at $600 \mathrm{~nm}$ using UV-Visible Spectrophotometer (Shimadzhu, India). A $0.4 \mathrm{ml}$ of hexadecane (Sigma, purity g $99 \%$ ) was added to $2.4 \mathrm{ml}$ of yeast suspension. The sample was vortexed for $2 \mathrm{~min}$ and left for $15 \mathrm{~min}$ to separate the hexadecane phase. Next, the yeast suspension was collected and transferred to a cuvette for the final absorbance measurement $\left(A_{0}\right)$ at $600 \mathrm{~nm}$. Adhesion of yeast cells to the hydrocarbons was evaluated as a percentage and it was calculated as $1-A_{1} / A_{0} \times 100$.

\section{Scanning electron microscopy}

The yeast cells with and without NE was harvested by centrifugation for $10 \mathrm{~min}$ at $5,000 \mathrm{rpm}$. Then, the pellet was coated onto the glass slide by dipping it into $2.5 \%$ glutaraldehyde for $2 \mathrm{~h}$ to fix the cells. Further, the slide containing the cells was dehydrated with water/alcohol solutions at various alcohol concentrations $(30,50$, and $70 \%$ ) for $10 \mathrm{~min}$ each. The samples were then coated with gold by sputtering under vacuum in argon atmosphere. The surface morphology of the coated sample was observed by a scanning electron microscope (FEI Quanta FEG 200).

\section{Anti yeast activity in real food system-apple juice}

The effect of nanoemulsion treated and untreated fruit juice was evaluated against food spoilage yeast, S. cerevisiae. The yeast culture was adjusted to $10^{7} \mathrm{CFU} / \mathrm{ml}$ at $600 \mathrm{~nm}$ using PBS. Fresh juice was collected and transferred to sterile bottles and inoculated with the adjusted yeast suspension. In test sample, the undiluted and tenfold diluted nanoemulsion was added to the yeast suspension. The suspension was diluted with sodium benzoate at a concentration of $0.3 \%$ and was considered as a negative control. The suspension diluted with PBS was used as negative control. Inhibition of yeast was studied in apple juice using time kill analysis method. The mixture was incubated at $4{ }^{\circ} \mathrm{C}$. At regular intervals $(4,12,24$ and $48 \mathrm{~h}$ ), the juice was serially diluted in PBS, plated in duplicates using a PDA, incubated for $48 \mathrm{~h}$ at optimum growth 
temperatures, and then enumerated for the viable count as $\mathrm{CFU} / \mathrm{ml}$. The growth medium with and without yeast culture was used as positive and negative controls in all treatments.

\section{Results and discussion}

Some EOs is applied as natural antimicrobial additives in the manufacturing and preservation of food to prolong the shelf life of various food products. The fact behind in these EOs possesses both antifungal and antimicrobial activity (Lis Balchin and Deans 1997; Cimanga et al. 2002). The application of synthetic and semi-synthetic antimicrobial compound can be reduced along with foodborne pathogens using EOs (Liang et al. 2012).

Selection of nanoemulsion based on thermodynamic stability study

Proper selection of nanoemulsion depends upon particle size distribution, oil type and emulsifier type that determine long kinetic stabilities. The nanoemulsion was formulated by adding water to the organic phase containing orange oil and Tween 80 as a surfactant $(1: 1,1: 2$ and 1:3 v/v). Further, this was subjected to ultrasonic emulsification, resulted in the formation of nanoemulsion. Using an emulsifier or surfactant for emulsification, that generates a strong repulsive force between the droplets which prevents flocculation and coalescence. To distinguish a nanoemulsion from microemulsion is difficult because nanoemulsion possess high kinetic stability in comparison to a microemulsion that is thermodynamically stable (McClements 2011).

Stability of the nanoemulsion was studied by centrifugation, heating-cooling cycle and freeze-thaw cycle for 1 month. The ratio of $1: 1(6,6$, and $82 \%)$ was found to be highly stable without any phase separation. Other formulations such as 1:2 and 1:3 were unstable during heating-cooling cycle and freeze thaw cycle. Samples containing relatively low amount of surfactant concentrations appeared milky and opaque initially. The emulsion after blending with sonicator, the turbidity was changed to bluish transparent. After sonication, the obtained nanoemulsion was more stable in size and appearance even after being diluted with water. Nanoemulsion containing relatively high surfactant concentrations showed evidence of particle growth after dilution (as demonstrated by an increase in sample turbidity a few min after dilution) (Rao and McClements 2011). It also got phase separated during thermodynamic stability study. Selected nanoemulsion was subjected to size distribution analysis by DLS.
Droplet size distribution

The Z-average diameter of the selected nanoemulsion was found to be $16 \mathrm{~nm}$, and it is shown in Fig. 1. Based on the thermodynamic stability study, 1:1 ratio was found to be highly stable without any phase separation. Prior to particle size analysis, dilute the sample with water to prevent multiple scattering effects. Particle size less than $90 \mathrm{~nm}$ in radius should be effectively prevented from creaming in the prepared nanoemulsion. Tween 80 is unsaturated fatty acid containing double bonds in the non-polar chains. The adsorption of surfactant molecules at the oil-water interface leads to decreased interfacial tension that favors the formation of ultrafine particles (Dai et al. 1997; Wang et al. 2009; Saberi et al. 2013).

Ultrasonic emulsification yields nanoemulsion with minimized droplet diameter with low polydispersity index. The droplet diameter was found in the range between 20 and $30 \mathrm{~nm}$ in diameter versus volume distribution. The polydispersity index (PI) of nanoemulsion was below 0.2 indicating very narrow distribution. PI gives an indication of the width of the size distribution. It also provides a measure of the homogeneity and stability of the droplet size in the emulsion.

Anti yeast activity: well diffusion study

Results from Fig. 2 showed that the formulated nanoemulsion at different temperatures and different time interval possessed anti-yeast activity against $S$. cerevisiae. When the orange oil nanoemulsion was assayed against the yeast by agar well diffusion method, the mean zones of inhibition obtained were between 40 and $45 \mathrm{~mm}$. These results indicate that the nanoemulsion retained its antiyeast activity for 1 month at different time interval and also at varying temperatures. Orange oil dissolved in DMSO showed reduced zone of inhibition $(20 \mathrm{~mm})$ against the tested yeast. This result indicates that the nanoemulsion formulation of orange oil has antimicrobial activity due to

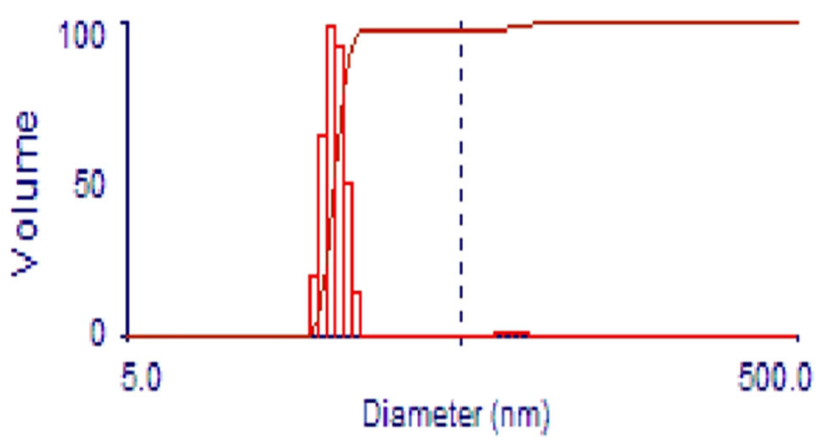

Fig. 1 Mean droplet size distribution of orange oil nanoemulsion by DLS 
Fig. 2 Agar well diffusion of nanoemulsion stored at different temperature and different time interval for 1 month

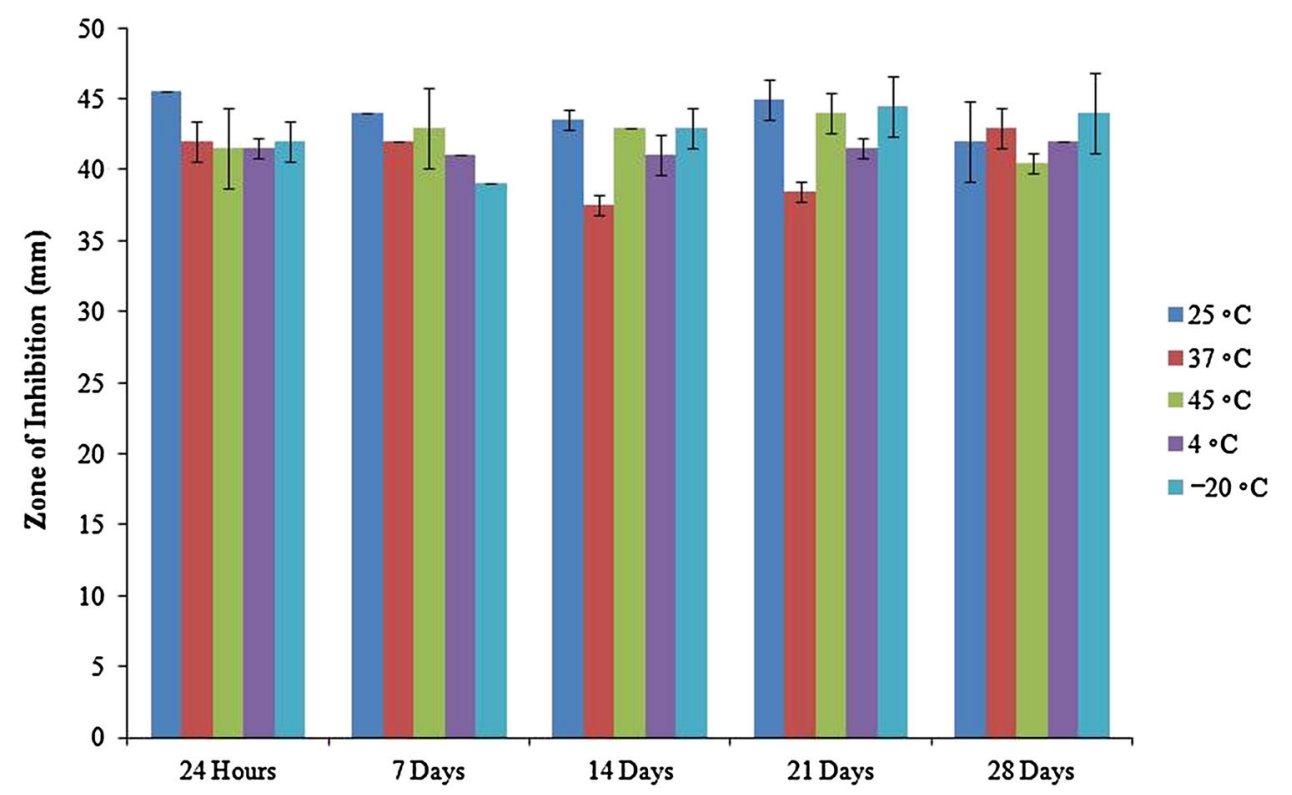

its nano-sized droplets. The results shown for antimicrobial activity by well diffusion method, the inhibition of yeast growth is noticeable due to any environmental stress were reported (different $\mathrm{pH}$ and temperature) and it is well correlated with the previous reports (Mert-Türk 2002). In addition to these effects, we have described here for the first time that antimicrobial activity of orange oil nanoemulsion against $S$. cerevisiae at different temperatures and time intervals for a period of 1 month.

Effect of orange oil nanoemulsion on yeast growth-MIC

The MIC of yeast is shown in Fig. 3. The lag phase is significantly increased when the nanoemulsion concentrations are being reduced especially at concentrations $<1 \mu \mathrm{l} /$

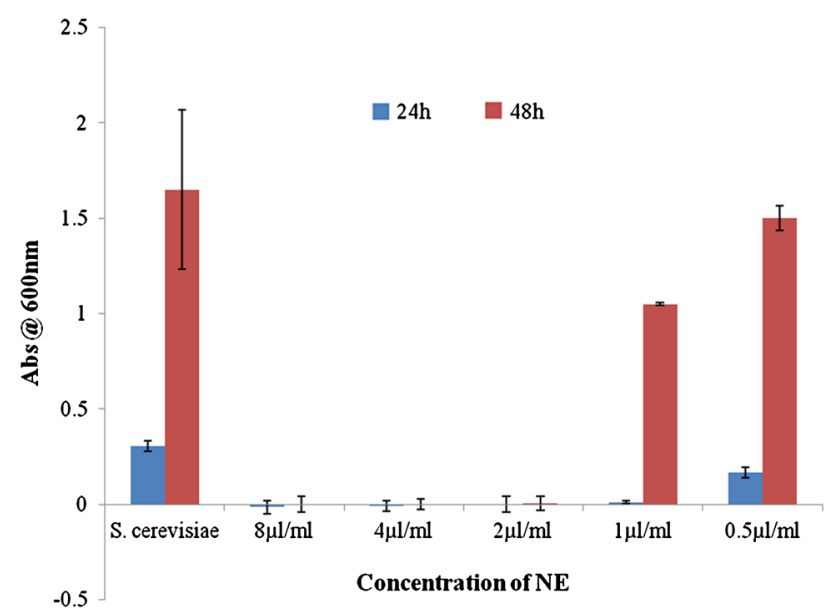

Fig. 3 Minimal inhibitory concentration (MIC) of orange oil nanoemulsion against Saccharomyces cerevisiae in growth medium ml. No growth was observed for higher concentration of nanoemulsion $(2-8 \mu \mathrm{l} / \mathrm{ml})$ during 24 and $48 \mathrm{~h}$ of incubation. The cell count assay was done indicating no or moderate changes compared to control. All of the orangebased products (characterized by high concentrations of limonene, $\alpha$-thujene, $\alpha$-myrcene, and linalool) tested in this research showed a lower inhibiting effect against the target yeast. On a wide screening of the antifungal activity of citrus based EOs, reduced antifungal activity was observed. Among, orange oil was shown to possess antifungal activity against Penicillium digitatum and $P$. italicum with respect to other citrus based oils. The different headspace composition can explain the reduced antimicrobial action. In fact, they have found a significant correlation between antimicrobial effects of citrus oil and the amount of some minor monoterpenes hydrocarbon, total monoterpenes and sesquiterpenes (Caccioni et al. 1998).

\section{Time-kill analysis}

The yeast, $S$. cerevisiae was tested to investigate the dynamic time kill analysis of orange oil nanoemulsions. As shown in Fig. 4, no viable cells were observed after $30 \mathrm{~min}$ treatment with tenfold diluted nanoemulsion. For 100-fold dilution, $10 \%$ viable cells were observed at $30 \mathrm{~min}$ treatment, whereas, complete loss of viability was observed after $4 \mathrm{~h}$ treatment with the nanoemulsion. In 1,000-fold dilution, $80 \%$ viable cells were observed after $24 \mathrm{~h}$. A complete loss of viability was observed after $48 \mathrm{~h}$ treatment with 1,000-fold dilution (data not shown). This result proves that nanoemulsion showed anti-yeast activity even on dilutions. According to kinetics of killing experiment, the undiluted form showed complete loss of viability within a min (data not shown) and these results are in 


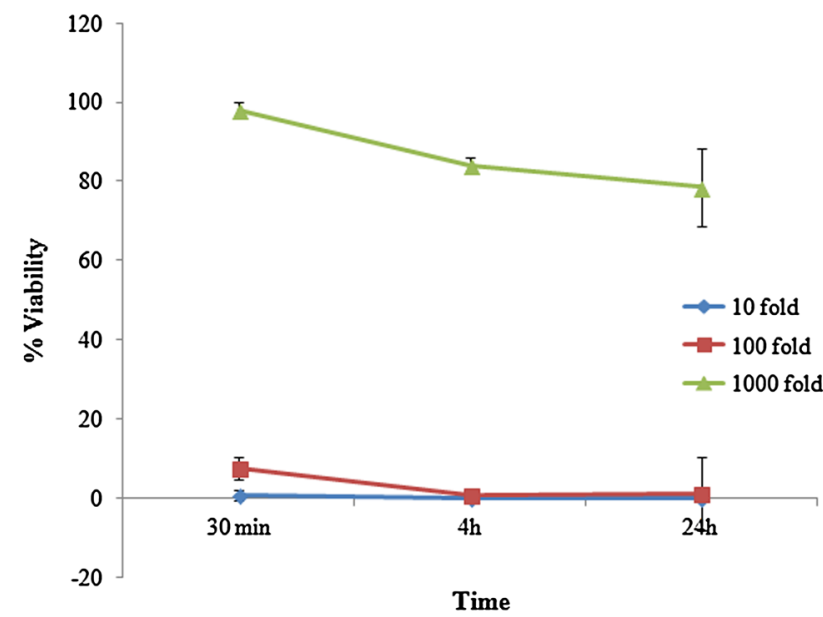

Fig. 4 Time kill analysis curve of orange oil nanoemulsion in growth medium

agreement with those previous reports (Al-Adham et al. 2003), whereas, oil-in-water microemulsion was effective against $S$. aureus or $P$. aeruginosa in only $45 \mathrm{~s}$. (Teixeira et al. 2007) From the previous investigations, it was found that the $\mathrm{O} / \mathrm{W}$ microemulsion was active against bacterial pathogens in 5 min for fungal pathogens and 2 min for Candida sp respectively. This is comparable to previous works (Zhang et al. 2008, 2009), and proved that the GMLloaded microemulsions have effective antibacterial activity within a min and antifungal systems with sporicidal activities against $A$. niger.

\section{MATH assay}

Hydrophobicity of treated cells and untreated cells with nanoemulsion was evaluated by MATH test. It is a measure of the tendency of cells attached to a surface. Yeast cell surface hydrophobicity after nanoemulsion treatment was expressed in terms of percentage. Control cells showed $2.5 \%$, and nanoemulsion treated cells showed $4.2 \%$. Nanoemulsion treated cells resulted in a greater increase in cell surface hydrophobicity when compared to yeast cells alone. The MATH result is considered as a measure of the hydrophobicity of microbial cell surface, which is evaluated by the partition of cells between water and hexadecane (Rosenberg and Rosenberg 1980). In this study, the adhesion of bacteria was evaluated with and without nanoemulsion of yeast cells in the context of food protection. This could be due to modification in the cell surface composition, as well as in the adsorption of an oil phase to the outer surface of bacteria.

\section{Cell damage study by SEM}

The anti-yeast activity of nanoemulsion was confirmed by scanning electron microscopy technique as shown in Fig. 5. Untreated yeast cells showed intact cells without any distortion in the morphology (Fig. 5a). Whereas, nanoemulsion treated $(15 \mathrm{~min})$ yeast cells were found to be distorted on the surface and also convoluted (Fig. 5b). This is in agreement with the results obtained (Karthikeyan et al. 2011). There were significant morphological changes were observed in S. mutans on treatment with nanoemulsion.

Anti yeast activity in real food system-apple juice

Inhibition of yeast was studied in apple juice by using time-kill analysis and is shown in Fig. 6. Very few viable cells were observed after 4,12 and $24 \mathrm{~h}$ and no viable
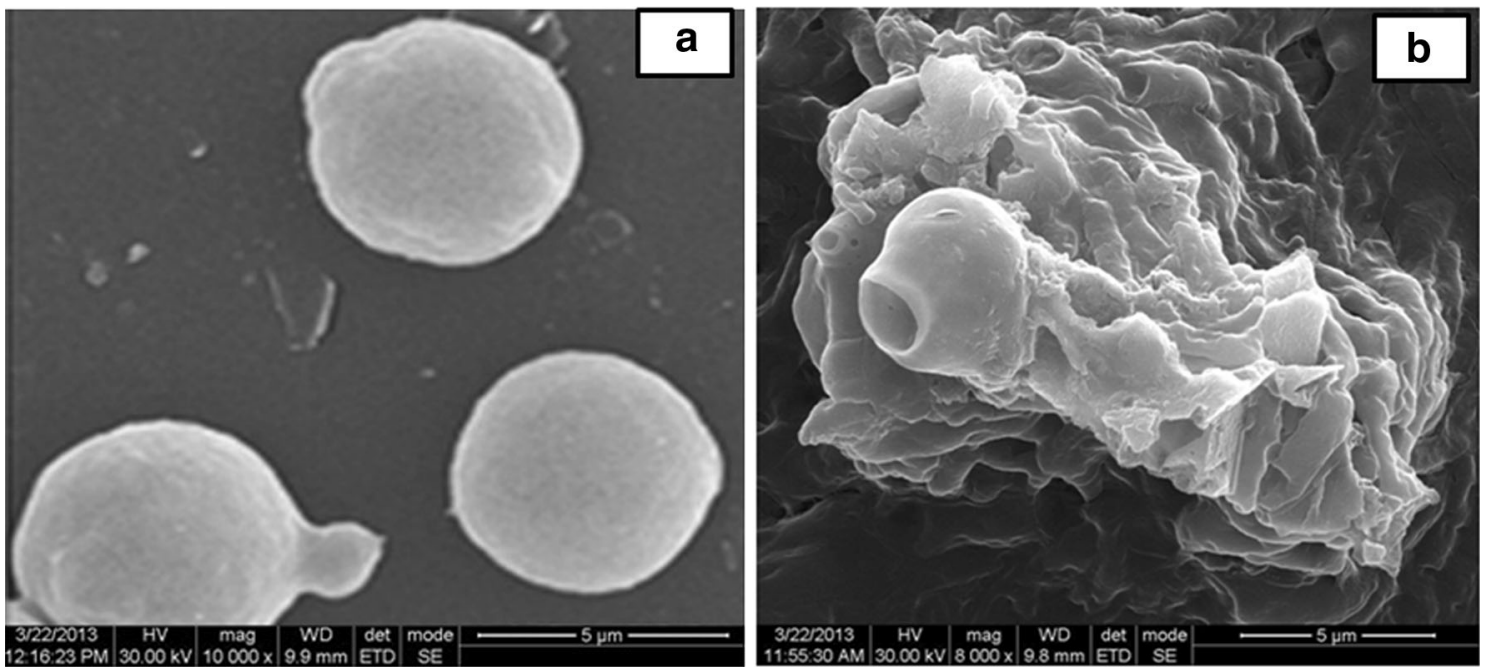

Fig. 5 Scanning electron microscopic image of Saccharomyces cerevisiae a yeast cells without nanoemulsion treatment; b orange oil nanoemulsion exposed yeast cells 
Fig. 6 Time kill analysis curve of orange oil nanoemulsion in real food system-apple juice

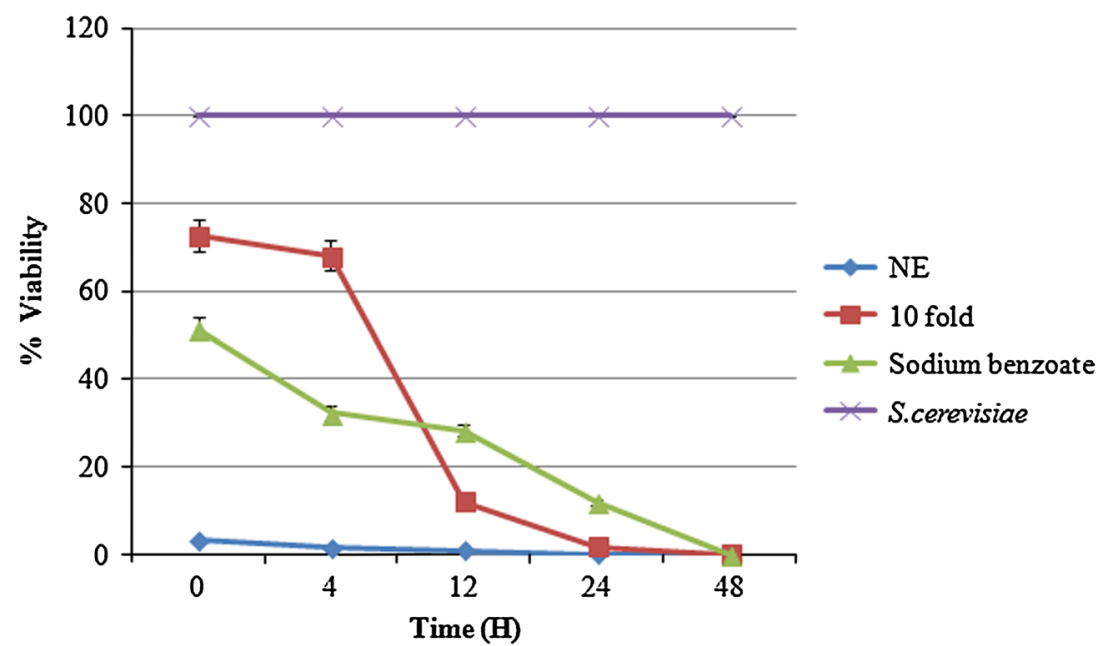

cells were observed after $48 \mathrm{~h}$ with undiluted orange oil nanoemulsion. For tenfold dilutions, $67 \%$ viable cells were observed after $4 \mathrm{~h}$ and $10 \%$ viable cells were observed after $12 \mathrm{~h}$. After $24 \mathrm{~h}$, extremely few viable cells were observed, whereas, complete loss of viability was observed after $48 \mathrm{~h}$ of treatment with nanoemulsion. This proves that nanoemulsion showed anti-yeast activity even after being diluted in real food system. Recently, the effects of EOs on growth parameters of yeast in apple juice shows that in the clear apple juice, the growth rate was significantly lowered by EOs in the case of $S$. cerevisiae and $S$. pombe as reported in literatures (Tserennadmid et al. 2011). Also recent report from Ghosh et al. 2014 with a use of eugenol loaded nanoemulsion was studied for shelf life of orange juice which preserves fruit juice against the native bacteria.

\section{Conclusion}

In conclusion, orange oil nanoemulsion possesses antiyeast activity, thus, making it a safer alternative to synthetic and semi-synthetic compounds. This nanoemulsion ensures physical and chemical stability of food in which it is applied. From this study, it can be concluded that orange oil nanoemulsion can be used for the preservation of food and beverage products.

Acknowledgments We deeply acknowledge VIT University, Vellore for funding this research work and Sophisticated Analytical Instrumentation Facility (SAIF), Department of Science and Technology (DST) at Indian Institute of Technology (IIT), Madras, for Scanning Electron Microscopy analysis facility used for this work.

Open Access This article is distributed under the terms of the Creative Commons Attribution License which permits any use, distribution, and reproduction in any medium, provided the original author(s) and the source are credited.

\section{References}

Al-Adham ISI, Al-Hmoud ND, Khalil E, Kierans M, Collier PJ (2003) Microemulsions are highly effective anti-biofilm agents. Lett Appl Microbiol 36:97-100

Burt S (2004) Essential oils: their antibacterial properties and potential applications in foods-a review. Int J Food Microbiol 94:223-253

Caccioni DRL, Guzzardi M, Biondi DM, Renda A, Ruberto G (1998) Relationship between volatile components of citrus fruit essential oils and antimicrobial actionon Penicillium digitatum and Penicillium italicum. Int J Food Microbiol 43:73-79

Chao SC, Young DG, Oberg CJ (2000) Screening for inhibitory activity of essential oils on selected bacteria, fungi and viruses. J Essent Oil Res 12:639-649

Cimanga K, Kambu K, Tona L, Apers S, De Bruyne T, Hermans N, Totté J, Pieters L, Vlietinck AJ (2002) Correlation between chemical composition and antibacterial activity of essential oils of some aromatic medicinal plants growing in the Democratic Republic of Congo. J Ethnopharmacol 79:213-220

Dai L, Li W, Hou X (1997) Effect of the molecular structure of mixed non-ionic surfactants on the temperature of miniemulsion formation. Colloid Surf A 125:27-32

Davidson PM, Harrison MA (2002) Resistance and adaptation to food antimicrobials, sanitizers, and other process controls. Food Tech 56:69-78

De Martino LDFV, Fratianni F, Nazzaro F (2009) Chemistry, antioxidant, antibacterial and antifungal activities of volatile oils and their components. Nat Prod Commun 4:1741-1750

Di Pasqua R, Hoskins N, Betts G, Mauriello G (2006) Changes in membrane fatty acids composition of microbial cells induced by addiction of thymol, carvacrol, limonene, cinnamaldehyde, and eugenol in the growing media. J Agric Food Chem 54:2745-2749

García-García R, López-Malo A, Palou E (2011) Bactericidal action of binary and ternary mixtures of carvacrol, thymol, and eugenol against Listeria innocula. J Food Sci 76:M95-M100

Ghosh V, Mukherjee A, Chandrasekaran N (2014) Eugenol-loaded antimicrobial nanoemulsion preserves fruit juice against, microbial spoilage. Colloids Surf B 114:392-397

Gill AO, Holley RA (2006) Disruption of Escherichia coli, Listeria monocytogenes and Lactobacillus sakei cellular membranes by plant oil aromatics. Int J Food Microbiol 108:1-9

Helander IM, Alakomi HL, Latva-Kala K, Mattila-Sandholm T, Pol I, Smid EJ, Gorris LGM, von Wright A (1998) Characterization of

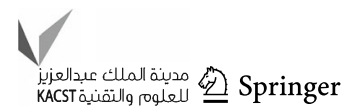


the action of selected essential oil components on Gram-negative bacteria. J Agric Food Chem 46:3590-3595

Holley RA, Patel D (2005) Improvement in shelf-life and safety of perishable foods by plant essential oils and smoke antimicrobials. Food Microbiol 22:273-292

Huang QR, Yu HL, Ru QM (2010) Bioavailability and delivery of nutraceuticals using nanotechnology. J Food Sci 75:R50-R57

Karthikeyan R, Bennett T, Amaechi H, Ralph R, Lee VA (2011) Antimicrobial activity of nanoemulsion on cariogenic Streptococcus mutans. Arch Oral Biol 56:437-445

Liang R, Xu S, Shoemaker CF, Li Y, Zhong F, Huang Q (2012) Physical and antimicrobial properties of peppermint oil nanoemulsions. J Agric Food Chem 60:7548-7555

Lis Balchin M, Deans SG (1997) Bioactivity of selected plant essential oils against Listeria monocytogenes. J Appl Microbiol 82:759-762

Ly MH, Aguedo M, Goudot S, Le ML, Cayot P, Teixeira JA, Le TM, Belin JM, Wache Y (2008) Interactions between bacterial surfaces and milk proteins, impact on food emulsions stability. Food Hydrocoll 22:742-751

McClements DJ (2011) Edible nanoemulsions: fabrication, properties, and functional performance. Soft Matter 7:2297-2316

Mert-Türk F (2002) Phytoalexins: defence or just a response to stress? J Cell Mol Biol 1:1-6

Naidu AS (2000) Natural food antimicrobial systems, 1st edn. CRC Press, Boca Raton, p 818

Oussalah M, Caillet S, Saucier L, Lacroix M (2007) Inhibitory effects of selected plant essential oils on the growth of four pathogenic bacteria: E. coli O157:H, Salmonella typhimurium, Staphylococcus aureus and Listeria monocytogenes. Food Control 18:414-420

Qian C, Decker EA, Xiao H, McClements DJ (2012) Physical and chemical stability of $\beta$-carotene-enriched nanoemulsions: influence of $\mathrm{pH}$, ionic strength, temperature, and emulsifier type. Food Chem 132:1221-1229

Rao J, McClements DJ (2011) Formation of flavor oil microemulsions, nanoemulsions and emulsions: influence of composition and preparation method. J Agric Food Chem 59:5026-5035

Rasooli I (2007) Food preservation-a biopreservative approach. Food 1:111-136

Rosenberg MGD, Rosenberg E (1980) Adherence of bacteria to hydrocarbons: a simple method for measuring cell-surface hydrophobicity. FEMS Microbiol Lett 9:29-33
Saberi AH, Fang Y, McClements DJ (2013) Fabrication of vitamin E enriched nanoemulsions factors affecting particle size using spontaneous emulsification. J Colloid Interface Sci 391:95-102

Sikkema J, de Bont JAM, Poolman B (1995) Mechanisms of membrane toxicity of hydrocarbons. Microbiol Rev 59:201-222

Solans C, Izquierdo P, Nolla J, Azemar N, Garcia-Celma MJ (2005) Nanoemulsions. Curr Opin Colloid Interface Sci 10(34): $102-110$

Stratford M (2006) Food and beverage spoilage yeasts. In: Quarol A, Fleet GH (eds) Yeasts in food and beverages. The yeast handbook, Springer, Berlin, pp 335-379

Tang S, Shridharan P, Sivakumar M (2013) Impact of process parameters in the generation of novel aspirin nanoemulsionscomparative studies between ultrasound cavitation and microfluidizer. Ultrason Sonochem 20:485-497

Teixeira PC, Leite GM, Domingues RJ, Silva J, Gibbs PA, Ferreira JP (2007) Antimicrobial effects of a microemulsion and a nanoemulsion on enteric and other pathogens and biofilms. Int $\mathrm{J}$ Food Microbiol 118:15-19

Tserennadmid R, Takó M, Galgóczy L, Papp T, Pest M, Vágvölgyi C, Almássy K, Krisch J (2011) Anti yeast activities of some essential oils in growth medium, fruit juices and milk. Int $\mathrm{J}$ Food Microbiol 144:480-486

Velluti A, Sanchis V, Ramos AJ, Egido J, Marín S (2003) Inhibitory effect of cinnamon, clove, lemongrass, oregano and palmarose essential oils on growth and fumonisin b1 production by Fusarium proliferatum in maize grain. Int J Food Microbiol 89:145-154

Wang L, Dong J, Chen J, Eastoe J, Li X (2009) Design and optimization of a new self-nanoemulsifying drug delivery system. J Colloid Interface Sci 330:443-448

Weiss J, Gaysinsky S, Davidson M, McClements DJ (2009) Nanostructured encapsulation systems: food antimicrobials. In: Gustavo BC, Alan M, David L, Walter S, Ken B, Paul C (eds) Global issues in food science and technology. Academic Press, San Diego, pp 425-479

Zhang H, Feng F, Li J, Zhan X, Wei H, Li H, Wang H, Zheng X (2008) Formulation of foodgrade microemulsions with glycerol monolaurate: effects of short-chain alcohols, polyols, salts and nonionic surfactants. Eur Food Res Technol 226:613-619

Zhang H, Shen FY, Weng P, Zhao G, Feng F, Zheng X (2009) Antimicrobial activity of a food-grade fully dilutable microemulsion against Escherichia coli and Staphylococcus aureus. Int J Food Microbiol 135:211-215 